\title{
COVID-19: Increased Risk to the Mental Health and Safety of Women Living with HIV in South Africa
}

\author{
John A. Joska ${ }^{1}$ - Lena Andersen ${ }^{1} \cdot$ Stephan Rabie ${ }^{1} \cdot$ Adele Marais $^{2}$ - Esona-Sethu Ndwandwa ${ }^{1} \cdot$ Patrick Wilson $^{3}$. \\ Aisha King $^{3} \cdot$ Kathleen J. Sikkema ${ }^{2,3}$
}

Published online: 29 April 2020

(C) Springer Science+Business Media, LLC, part of Springer Nature 2020

COVID-19 is a global health crisis. While involvement of the respiratory system is the primary cause of transmission and morbidity, there is increasing interest in the individuallevel mental health consequences of this pandemic. Even as many countries are struggling to treat an overwhelming number of patients acutely infected with COVID-19, the epidemic in South Africa raises unique challenges. A lockdown implemented by the government at the initial stages of the outbreak stemmed the spread of infection, preventing the healthcare system from being inundated with cases. While the effect of the lockdown on "flattening the curve" remains to be seen, the mental health and wellbeing of the South African population is at increased risk.

Our clinical experience working with women with HIV infection (WLHIV) and a history of psychological trauma suggests that they may have several anxieties linked to the impact of a life-threatening infection on their well-being and that of their children. We propose that the early stages of the COVID-19 epidemic in South Africa may exert the following deleterious mental health effects on WLHIV: (1) re-kindling of trauma related to restrictions applied to specific communities under Apartheid, (2) increased anxieties related to potential infection with a fatal virus, (3) associated behavioural avoidance leading to further reduced access to care and medication adherence, and (4) increased rates of domestic violence resulting from lockdown.

John A. Joska

john.joska@uct.ac.za

1 Department of Psychiatry and Mental Health, HIV Mental Health Research Unit, Neuroscience Institute, University of Cape Town, Cape Town, South Africa

2 Department of Psychiatry and Mental Health, University of Cape Town, Cape Town, South Africa

3 Department of Sociomedical Sciences, Mailman School of Public Health, Columbia University, New York, USA

\section{Trauma Rooted in Apartheid}

Older WLHIV would recall the restrictions placed on persons of colour before our first democratic election, including severely curtailed movement enforced by the police and the military. While COVID-19 restrictions apply to all South Africans, those traumatised before 1994 may report increased anxiety and fear as a result of re-living past experiences. In order to avoid negative associations of lockdown, WLHIV may avoid travelling. One consequence may involve missing clinic visits and not obtaining necessary medication.

\section{Another Infection to Fear}

Another likely consequence of COVID-19 for WLHIV is anticipatory anxiety. The novel coronavirus adds a superlayer of infection to the lives of these individuals. Co-morbid and opportunistic infection is no stranger to HIV-affected communities. Tuberculosis rates are approximately $20 \%$, and many in these communities have experienced other fungal and viral infections $[1,2]$. At present, we know that between $10-20 \%$ of individuals infected with COVID-19 will develop severe respiratory syndrome requiring hospital admission, and that approximately 1-3\% will die from complications [3]. Less is known about rates of hospital admission and mortality among immuno-compromised communities, where lung health is often depleted. We anticipate severe respiratory syndromes will be more prevalent in our population.

\section{Impacts on Access to Care}

Prior to the ART roll-out in 2005 in South Africa, becoming HIV infected was a death sentence. Even today many untreated persons still die from HIV in poorer communities. In the absence of effective treatment for COVID-19, women 
may re-experience associated fears, including involuntary abandonment of dependent children. Persons, households and communities in South Africa have been given information about a highly infectious, sometimes fatal respiratory virus, and been warned that their access to usual medical care might soon be limited if lockdown regulations are not followed [4]. This messaging has created tension for women who need to visit clinics to obtain HIV care and medication while feeling obligated to uphold the lockdown and prevent transmission of COVD-19.

\section{Interpersonal Violence and Sexual Trauma}

Interpersonal violence and sexual trauma are highly prevalent among this population [5, 6]. Our group has previously shown that nearly two-thirds of WLHIV have experienced sexual trauma and that many do not disclose this history unless asked under research or strict clinical conditions $[7,8]$. The consequences of these experience(s) include increased rates of depression and post-traumatic stress disorder [9], and increased likelihood of behavioural avoidance patterns [6, 10-12]. An HIV diagnosis may itself aggravate traumatic experiences; many women either relate their HIV diagnosis indirectly to experience of trauma or acquired HIV during a sexual assault $[6,13,14]$. These combined effects, in the context of women living with HIV in periurban, often resource-limited settings, may result in delays accessing HIV care, missing clinic appointments and poor medication adherence.

WLHIV with a history of sexual trauma already live with high levels of anxiety, including hyper-arousal and avoidance symptoms [8]. They cope poorly with additional stressors $[11,15]$. Crucially, the lockdown prohibits WLHIV from seeking social support from persons outside of their household, including friends, family and religious groups. These restrictions complicate their journey to health. WLHIV often live in chronically under-resourced communities characterised by high rates of violence, substance use, and limited opportunities for employment. Beyond their immediate health-related needs, women rely on multiple socioemotional resources to cope with their trauma history and living with HIV. Under current restrictions, access to "routine" services, such as social work or counselling, are not considered essential and are disallowed.

\section{Increased Interpersonal Violence}

There is an additional unintended consequence of the national lockdown: a surge in domestic violence. Both globally and in South Africa there have been increased reports of gender-based and domestic violence since the implementation of COVID-19-enforced lockdowns. During the first week of the lockdown in South Africa, 87,000 cases of domestic and inter-personal violence were reported [16]. Individuals are stressed, frustrated and confined in close quarters. Vulnerable persons will be at heightened risk and rates of trauma will escalate. With rates of domestic violence increasing, any coping strategies our future participants may have are at risk of dissipating. Considering that many WLHIV have histories of intimate partner violence and many are currently in abusive relationships, the restrictions placed on their movement may impact their safety. In addition, many women will have to manage an increase in parenting demands—often without any emotional or practical support from their abusive partners. Furthermore, for women who have not disclosed their HIV status to an abusive partner, accessing HIV care may not be feasible without placing them at risk for violence. At a time when continuity of HIV-care engagement could provide reassuring consistency and mediate fears regarding COVID-19, WLHIV may instead be left unsupported and at heightened risk for domestic abuse.

\section{A Coherent Response is Needed}

Our group has previously piloted a coping intervention with HIV-infected women aimed at reducing avoidant coping and improving medication adherence and retention in care [8]. A randomised controlled trial to test the effectiveness of the intervention is scheduled to commence in Cape Town, South Africa in the coming months (1R01MH118004). As South Africans will need to remain partially restricted in order to maintain control over the effects of COVID-19, an instinctive response is to provide "remote" services or "telepsychiatry". Indeed, these models can be highly effective in providing support, counselling and psychotherapy [17]. However, this response pre-supposes that the patient has access to the internet, reliable tele-communication, and mobile data, not to mention privacy. These prerequisites are unfortunately not consistently available in impoverished communities among which we work, necessitating novel and contextually relevant responses.

One option is for the South African government to classify psychological treatments as essential. The risk of COVID-19 transmission is limited when interactions occur on an individual one-on-one basis. For women on antiretroviral therapy who are still able to access HIV care, psychological treatment should be available and fast-tracked to reduce waiting times. Clinic managers and care providers need to consider this service essential. A second option is to train community health workers who are currently employed to find and track COVID-19 cases within resource-constrained communities, in basic counselling and support. 
Addressing the mental health needs of WLIHV needs to be as rapid as the general and health response has been. It will require recognition by health system planners, before another epidemic of household trauma exacerbates the physical and mental health conditions of an already traumatised population. Should COVID-19 become a generalised epidemic in South Africa, we will need to address the further impact of morbidity, mortality, and the ensuing grief and loss

\section{References}

1. Ismail T, Lee C. HIV associated opportunistic pneumonias. Med J Malays. 2011;66:76.

2. Limper AH, Adenis A, Le T, Harrison TS. Fungal infections in HIV/AIDS. Lancet Infect Dis. 2017;17:e334.

3. Wang C, Horby PW, Hayden FG, Gao GF. A novel coronavirus outbreak of global health concern. Lancet. 2020;395:475.

4. Disaster Management Act: Regulations to address, prevent and combat the spread of Coronavirus COVID-19: Amendment. 2020

5. Seedat $\mathrm{S}$. Interventions to improve psychological functioning and health outcomes of HIV-infected individuals with a history of trauma or PTSD. Curr HIV/AIDS Rep. 2012;9:344.

6. Gass JD, Stein DJ, Williams DR, Seedat S. Gender differences in risk for intimate partner violence among south african adults. J Interpers Violence. 2011;26:2764.

7. Sikkema KJ, Choi KW, Robertson C, Knettel BA, Ciya N, Knippler ET, et al. Development of a coping intervention to improve traumatic stress and HIV care engagement among South African women with sexual trauma histories. Eval Program Plann. 2018;68:148.

8. Sikkema KJ, Mulawa MI, Robertson C, Joska JA. Improving aids care after trauma (ImpACT): pilot outcomes of a coping intervention among HIV-infected women with sexual trauma in South Africa. AIDS Behav. 2018;22(3):1039-52.

9. Machtinger EL, Wilson TC, Haberer JE, Weiss DS. Psychological trauma and PTSD in HIV-positive women: a meta-analysis. AIDS Behav. 2012;16:2091.

10. LeGrand S, Reif S, Sullivan K, Murray K, Barlow ML, Whetten $\mathrm{K}$. A review of recent literature on trauma among individuals living with HIV. Current HIV/AIDS Reports. 2015;12:397.

11. Aaron E, Criniti S, Bonacquisti A, Geller PA. Providing sensitive care for adult HIV-infected women with a history of childhood sexual abuse. J Assoc Nurses AIDS Care. 2013;24:355.

12. Hatcher AM, Smout EM, Turan JM, Christofides N, Stöckl H. Intimate partner violence and engagement in HIV care and treatment among women: a systematic review and meta-analysis. AIDS. 2015;29:2183

13. Jewkes R, Abrahams N. The epidemiology of rape and sexual coercion in South Africa: an overview. Soc Sci Med. 2002;55:1231

14. Jewkes R, Penn-Kekana L, Levin J, Ratsaka M, Schrieber M. Prevalence of emotional, physical and sexual abuse of women in three South African provinces. S Afr Med J. 2001;91:421.

15. Campbell JC, Baty ML, Ghandour RM, Stockman JK, Francisco $\mathrm{L}$, Wagman J. The intersection of intimate partner violence against women and HIV/AIDS: a review. Int J Injury Control Saf Promot. 2008; $15: 221$.

16. Chothia A. Lockdown: 87000 cases of gender-based violence reported. 2020. https://www.thesouthafrican.com/news/gende r-based-violence-reported-during-lockdown-cele/.

17. Hilty DM, Ferrer DC, Parish MB, Johnston B, Callahan EJ, Yellowlees PM. The effectiveness of telemental health: a 2013 review. Telemed e-Health. 2013;19:444.

Publisher's Note Springer Nature remains neutral with regard to jurisdictional claims in published maps and institutional affiliations. 